REVIEW

\title{
Interference with p53 functions in human viral infections, a target for novel antiviral strategies?
}

Pedro A. Lazo and Claudio R. Santos

Experimental Therapeutics and Translational Oncology Program, Instituto de Biología Molecular y Celular del Cáncer, Consejo Superior de Investigaciones Científicas (CSIC) Universidad de Salamanca, Campus Miguel de Unamuno, E-37007 Salamanca, Spain

Running title: Viral manipulation of p53 responses

* Footnotes:

The authors declare that they have no competing interests. P.A.L. was supported by grants from spanish Ministerio de Educación, Ciencia e Innovación [SAF2010-14935, Consolider CSD20070017], Junta de Castilla y León [Conserjería de Educación CSI-006A11-2, GR-15], and KutxaFundación INBIOMED. C.R.S was funded by Fundaçao para Ciência e a Tecnologia (Portugal).

Corresponding author: Dr. P. A. Lazo, IBMCC-Centro de Investigación del Cáncer, CSICUniversidadde Salamanca, Campus Miguel de Unamuno, E-37007 Salamanca, Spain. Email: pedro.lazo@usal.es; plazozbi@usal.es.

Tel: (34) 923294804. Fax: (34) 923294795 


\section{Abbreviations used:}

HBV X, HBV protein X; HCMV, human cytomegalovirus; LANA, latency-associated nuclear antigen; vIRF1, viral interferon regulatory factor; VSV, vesicular stomatitis virus; MCPyV, Merkel cell polyomavirus; Adv, adenovirus; ATM, Ataxia telangiectasia mutated; ATR, ATM related; CHK1, checkpoint kinase 1; CHK2, checkpoint kinase 2; JNK, c-Jun N-terminal kinase; VRK1, vaccinia-related kinase 1; PLK3, polo like kinase 3; CK1, casein kinase 1; PEL, primary effusion lymphoma; AKT, Proto-oncogene c-Akt/Protein kinase B; TAD, transactivation domain; PI3K, phosphoinositide-3-kinase; Akt, v-akt murine thymoma viral oncogene. 


\begin{abstract}
Viral infections cause a major stress in host cells. The cellular responses to stress are mediated by p53, which by deregulation of cell cycle and apoptosis, may also be part of the host cell reaction to fight infections. Therefore, during evolutionary viral adaptation to host organisms, viruses have developed strategies to manipulate host cell p53 dependent pathways to facilitate their viral life cycles. Thus, interference with p53 function is an important component in viral pathogenesis. Many viruses have proteins that directly affect p53, while others alter the regulation of p53 in an indirect manner, mediated by hdm2 or akt, or induction of interferon. Rescue of p53 activity is becoming an area of therapeutic development in oncology. It might be feasible that manipulation of p53 mediated responses can become a therapeutic option to limit viral replication or dissemination. In this report, the mechanisms by which viral proteins manipulate p53 responses are reviewed, and it is proposed that a pharmacological rescue of p53 functions might help to control viral infections.
\end{abstract}

Keywords: p53, therapy, virus, infection

\title{
Introduction
}

Cellular stress responses aim to protect cells from many different types of stress damage, endogenous and exogenous, and among of these viral infections represent a major type of cellular stress. Viruses require a suitable host cell to carry out their life cycle. In infections, viruses aim to use the host cell to guarantee their own survival and propagation. Therefore, the human pathology observed in virally infected individuals is a consequence and side effect, but not the aim of the virus in the course of an infection. Actually a very pathogenic infection might be self limiting, because it runs the risk of eliminating suitable host individuals for viral transmission and perpetuation. However, if cellular stress responses were very successful, viral infections probably would not be viable, since they would be aborted by host cells before completion of the viral life cycle. These cellular stress responses are largely mediated by p53 [1, 2]. Therefore, during viral evolution and their adaptation to human host cells, viruses have acquired different strategies to manipulate cellular stress responses, 
mediated in large part by p53, which will permit viral survival by allowing completion of all the steps in the viral life cycle, without compromising host viability. The rapid viral life cycle also means that viral effects on p53 are transitory, and perhaps function differently at specific times within the host cell cycle. For many human viruses, for example HBV or HPV, their viral pathogenic effects are very difficult to study in synchronized cell cultures, and therefore these effects cannot be easily detected due to their short duration and the heterogeneity of infected cells. In this work is presented an overview of how p53 functions can be interfered with by viral proteins from many different viruses, and is thus a common aspect to all infections that can become a potentially useful therapeutic target.

\section{The $\mathbf{p} 53-\mathrm{Hdm} 2$ regulatory circuit as mediator of cellular stress responses, a prime target for viral proteins}

The p53 protein functions as a common integrator and transmitter of signals originated in signaling pathways which are activated in the cellular response to many different types of stress, such a DNA damage, changes in osmolarity, temperatute and changes in oxygen levels among others [3, 4]. The response induced by p53 [5] regulates biological functions, ranging from cell cycle regulation [6], induction of apoptosis [7], autophagy [8] or senescence [9], all aiming to protect the cell and the individual organism. The p53 protein also controls mechanisms implicated in DNA replication by its contribution to cell cycle checkpoints [10], and can also initiate responses that lead to cell death [11]. Mechanistically, the p53 protein functions as a transcriptional regulator of genes implicated in these different cellular functions [12, 13], and because of its regulatory roles p53 behaves as a tumor suppressor gene $[14,15]$.

The p53 protein has a short half-life and its intracellular basal levels are low in normal cells. In response to stress p53 is immediately activated by phosphorylation mediated by different kinases, which represent different response pathways to cellular stress of which the response to DNA damage, have received most of the research attention for its oncogenic consequences [15-17]. This rapid phosphorylation of p53 results in its stabilization and accumulation, which is mediated by a large number of different cellular kinases, such as ATM, ATR, CHK1, CHK2, JNK, VRK1, PLK3, CK1 among others [18]. Seven different residues in the p53 N-terminal trans-activation domain 1 (TAD1) 
are targeted by kinases [18], and the resulting patterns of p53 phosphorylation determine its protein interactions with transcriptional activators, or negative regulatory proteins, such as hdm2/mdm2 and other ubiquitin ligases [18-20], some might be viral proteins, and in this way phosphorylation determines the specificity of the response, which may be different depending on cell type. This phosphorylated N-terminal domain promotes binding to transcriptional coactivators, such as p300 or PCAF, which acetylates p53 in its carboxy terminus [21]. The activated p53 protein determines the type of cellular response which range from activation of repair mechanisms, stopping cell cycle or indecent apoptosis and autophagy. When these normal biological responses have completed their protective role, the activation of p53 is reverted; otherwise it will be deleterious for the cell. The reversion is necessary because the persistent accumulation of p53 is deleterious to the cell by permanently blocking cell cycle or by induction of apoptosis, which are not compatible with life. But if cellular protection against stress is successful, the reversion of the effects induced by p53 allows cell cycle progression and cell survival. This reversion is achieved by p53 that, as part of its transcriptional response, induces HDM2 gene expression, which is its negative regulator. The hdm2 protein is an E3 ubiquitin-ligase that ubiquitylates p53 in its C-terminal oligomerization domain and marks it for degradation in the proteasome [22-25] forming an autoregulatory loop [26]. In that way, the p53 response is turned off and the biological consequences of a persistent accumulation of p53 prevented (Figure 1). The core of this autoregulatory mechanism is the formation of a complex between the p53 and hdm2 proteins. Hdm2 has a hydrophobic pocket in its N-terminal region, residues 26-108, that interacts with the hydrophobic side of an alpha helix in dephosphorylated p53 [27]. The p53 interaction with hdm2 is blocked by phosphorylation of p53 in Ser15, Thr18 or Ser20, which alters the alpha helix [27], and thus prevents degradation of p53 in the proteasome [19]. Thus a functional interaction between p53 and mdm2 requires dephosphorylation of p53, a process that has received relatively little attention, but that is required for downregulation the deleterious consequences of a persistent accumulation of p53.

However, phosphorylation of p53 in response to viral infection has not been studied in general, although it is very likely to play an important role in viral infections and it might also be mediated by viral kinases in addition to cellular kinases. Thus no specific p53 phosphorylation 
patterns are known in the context of most viral infections, with some exceptions such as EBV or HSV. All viral effects on the p53 pathway are very likely to be transient, since they will be important, and probably different, at different times within the viral life cycle in acute infections. Also it is not known how p53 responses are blocked in latent or chronic infections.

Alternatively, the p53-hdm2 interaction can also be altered by kinases targeting hdm2. Hdm2 is phosphorylated by several cellular kinases, but the effect varies depending on the residue phosphorylated [28]. Some hdm2 phosphorylations facilitate degradation of p53. Thus, PI3-K/Akt, associated with survival signaling, phosphorylates hdm2 in residues Ser166 and Ser186 in close proximity to its nuclear localization and nuclear export signals [28], and these phosphorylations promote its nuclear accumulation and facilitate p53 degradation [29]. No viral kinase directly phosphorylating hdm2 has yet been identified, but alternatively it is possible that viruses might activate the cellular PI3-K/Akt pathway to reach a similar effect. Another kinases phosphorylate hdm2 in other residues leading to its degradation [28, 30], so that p53 is not ubiquitylated and cannot be degraded, thus p53 accumulates in cells because can induce cell death. ATM phosphorylates hdm2 in Ser395 and induces mdm2 degradation, indirectly permitting p53 stabilization and accumulation because it cannot be degraded [31]. Also c-Abl phosphorylates hdm2 in multiple sites, but the most important is Tyr394, preventing downregulation of p53, which is accumulated inducing apoptosis [32]. Thus a virus by activation of this second type of hdm2 phosphorylation pathway can manipulate it for viral release.

Viral infections constitute a major type of cellular stress, but the role of p53 in this context has not been extensively characterized, and most of the information is derived from few viruses, although circumstantial evidence for its implication is available for many of them. The roles of the p53 protein can have a dual effect in viral infections, as an antiviral defense in the context of cellular stress response; or alternatively, because of its role in regulating cell cycle and cell death, might be targeted and adjusted by viral proteins to facilitate their own viral life cycle. In this overview we look at the role that manipulation of p53 might play in the pathogenesis of viral infections. Most viruses have acquired, through evolution and adaptation to host cells, strategies to interfere with p53 functions. Thus, many viruses have at least one viral protein that directly interacts with p53. Although 
the functional consequences of this interaction may vary, its consequences in the cell have received a relatively limited attention compared to other aspects of viral biology. Studies on temporal changes of p53, during short viral life cycles, have not in general being performed, particularly since p53 might even have different roles depending on the requirements and stage of the infection, such as viral replication, viral assembly or viral release, as well as of the phase of the cell cycle. Therefore, p53 responses can be subverted by viruses in different ways for their adaptation to sequential stages in viral life cycles. Control of cell cycle progression can be manipulated to permit viral replication, and cell death can be a determinant factor for lytic phases, elimination of infected cells, or alternatively permit viral release, and thus is a prime target for biological selection in viral evolution and adaptation to host cells.

\section{Viral mechanisms for manipulation of p53-mediated responses}

Viruses can functionally interfere with p53 mediated cellular responses by several mechanisms in which different components of the p53-hdm2 autoregulatory loop are targeted by viral proteins. Among them are direct viral protein interactions with p53, phosphorylation of p53 by viral kinases, ubiquitylation of p53 by viral proteins, activation of hdm2 by viral proteins and other indirect mechanisms. These are outlined in Fig. 1, and summarized in Table 2.

\section{Interaction of viral proteins with p53}

The simplest mechanisms by which viruses can interfere with p53 are mediated by a direct interaction between viral proteins and p53, and thus alter p53 dependent functions like cell cycle or apoptosis.

Papovaviruses. Papovaviruses are a group of small DNA viruses (SV40, JCV and BHK) whose role in human pathology is not clear. The large T-antigen of SV40 directly interacts with the p53 DNA binding domain and can inhibit p53 mediated responses [33, 34]. The crystal structure of this p53 complex is known [35] and can be used for drug design. Human JCV large-T protein inhibits viral DNA replication by interacting with the DNA binding-region of p53, which is where most p53 mutations detected in cancer are located. Some p53 mutations result in loss of p53 large-T interaction, 
as is the case with the frequent mutation at position R273 relieving the inhibition on viral replication, but not in the case of mutations in position R175 [36]. The oncogenic role of JCV is still controversial [37]. Interestingly in Merkel carcinoma cells, a malignancy with dermoneurendocrine origin and associated to MCPyV (Merkel cell polyomavirus), with a higher viral load there is a lower level of p53 protein [38], which can contribute to tumor cell survival, but how it contributes to viral life cycle is not known.

Adenovirus: Adenoviruses mainly cause upper tract respiratory infections. In infected cells, the E1B protein of Mr 55,000 [29] binds to p53 in cooperation with E4-ORF6 protein, targets p53 for active degradation [39, 40] and thus inhibits p53 acetylation by pCAF [41], reducing gene expression of proapoptotic Bax [42] and preventing apoptosis [43]. Another adenoviral protein, E4-ORF3 also inactivates p53 by forming a nuclear structure that induces de novo histone-3 methylation (H3K9m3) in heterochromatin located at promoters targeted by p53, in this way p53-dependent activation of transcription is blocked [44]. However, at a different time in infection a p53 dependent apoptosis is necessary for a productive adenoviral infection, in which p53 is important for the cytopathic effect, but the underlying mechanism is not known [45].

Epstein-Barr Virus: EBV is associated with endemic Burkitts lymphomas and nasopharyngeal carcinomas. EBV represents a very interesting case, since two viral proteins can interact with p53, one during latency and the other in the lytic phase. During latency, the EBNA3C protein directly interacts with the C-terminal region of p53, prevents binding to DNA and inhibits activation of transcription, by this mechanism it also rescues cells from the apoptosis induced by p53 [46, 47]. In the EBV switch from latent to lytic infection, the intermediate-early BZLF1 lytic viral transcription factor directly interacts with the C- terminal region of p53 [48, 49], and interferes with the transactivation of genes induced by p53 in lymphoid cells [48], which can be overcome by overexpression of p53 that inhibits the role of BZLF1 in the disruption of viral latency [48]. 
Human herpes virus 6B. Herpes viruses cause vesicular epithelial lesions. In HHV-6-infected cells, early in infection, the U14 protein coimmunoprecipitates and colocalizes with p53 in dot like particles. Both proteins, U14 and p53, are incorporated into virions suggesting that p53 is likely to play an important role in viral infection, which has not yet been characterized [50]. There is a second viral protein, ORF-1 (DR-7), which also binds to p53 and inhibits transcription in cells from Hodgkin's lymphomas [51]. The loss of p53 in infected cells favors the induction of cytopathic effects. Also in cells infected with HHV6B there is phosphorylation of p53 in Ser20 induced by CK1 (casein kinase 1) [52], this specific phosphorylation leads to stabilization and accumulation of p53 [18]. All the data indicate that in epithelial cells, some of the functions of p53 leading to cell-cycle arrest and apoptosis is restrained in HHV6B infections [53].

HHV8 (Kaposi's sarcoma herpesivirus): KSHV infection can cause three different types of tumors: Kaposi's sarcoma, a plasmablastic variant of multicentric Castelman's disease and an AIDS-related form of B cell lymphoproliferative disorder called primary effusion lymphoma (PEL), which is a very aggressive disease. KSHV has a protein named viral interferon regulatory factor 1 (vIRF1), or latency-associated nuclear antigen (LANA) [54, 55]; and another K-bZIP (open reading frame K8) protein that has a basic region-leucine zipper (bZIP) [56]. These proteins can interact with the DNA binding region of p53 and inhibit p53-dependent transcription [56]. LANA also facilitates p53 ubiquitination leading to it removal by degradation in the proteasome and in that way contributes to viral persistence [57]. Furthermore, LANA/ vIRF1 can also interact with ATM, a DNA-damage response kinase, inhibiting its activity and resulting in a decrease in the p53 specific phosphorylation in S15 within its transactivation domain [58]. The functional result of the lack of p53 activation is a compromised cellular response to DNA damage mediated by p53, which may allow for progression of the viral infection when cellular stress responses are defective.

Hepatitis B virus: HBV is the cause of most cases of hepatitis and hepatocarcinomas. In HBV infections p53 function is affected by a unique viral protein by two mechanisms. The HBV protein X (HBV X) represses TP53 gene expression [59], and also retains p53 in the cytoplasm causing a block 
of p53 nuclear functions [60]. This process abrogates the infected cell response to genotoxic damage, and thus might contribute to oncogenesis by HBV [61]. But also in cells expressing HBV $\mathrm{X}$, the phosphorylation of p53 in six residues within its $\mathrm{N}$-terminal domain is not affected, particularly in Ser15 [62], which suggest a good stress response. These contradictory data reflects the existence of differential infection requirements that need to be clarified. Recently, a double mutation in HBV X (K130M and V130I) protein, which also interacts with p53, has been shown to inhibit p53-dependent transcription and colony formation [63].

HCV: Human hepatitis $\mathrm{C}$ virus is also implicated in liver cancer and liver failure. This virus expresses the NS5A protein that interacts with p53 blocking p53-dependent transcription and prevents apoptosis $[64,65]$, and in that way can contribute to tumour development.

$\underline{H I V-1:}$ : This virus causing AIDS expresses a protein vpr, which by its C-terminal region indirectly inhibits p53 activation of transcription, although this action does not require a direct interaction between these two proteins [66]. This inhibition of p53 derepresses the activation of HIV-1 mediated by the Sp1transcription factor $[67,68]$.

Influenza: In cells infected with influenza virus, the non-structural NS1 protein of influenza A interacts directly with p53, inhibits activation of p53-dependent transcription and prevents induction of apoptosis [69], but some NS1 variants maintain the inhibition of transcription, but have no effect on apoptosis [70]. These data suggest a dual role for the NS1 protein that needs to be further characterized [71].

\section{Phosphorylation of p53 by viral protein kinases}

Phosphorylation of p53 is a major mechanism regulating p53 functions [18]. But only one viral kinase has been identified so far; Vaccinia virus B1(B1R) kinase is able to extensively phosphorylate p53 [72]. This situation requires additional research because kinases might have potential uses as therapeutic targets for existing or novel kinase inhibitors [73]. Alternatively viral 
proteins can affect cellular kinases and indirectly regulate p53, a topic particularly well known in some herpes viruses. Indirect phosphorylation by stabilization of p53 and disruption of the interaction with hdm2 will facilitate p53-induced effects. The phosphorylation of p53 in infected cells has been mainly studied in herpes viruses such as HSV [74], EBV [49], HCMV [75].

Vaccinia virus: Poxviruses, of which vaccinia is the most characterized member, have an early protein B1R that is a ser-thr kinase [76]. B1R is necessary for viral DNA synthesis and replication of a large viral genome [77]. In addition to its roles regulating viral proteins, B1R also affects cellular proteins so contributing to its life cycle. It has been observed that infected cells have a delay in cell cycle progression [78]. B1R is able to phosphorylate the c-jun protein and modulate the cellular stress response to the viral infection [79]. Also B1R phosphorylates p53 in multiple sites causing a transient and short accumulation followed by its degradation [72]. This transient accumulation of p53 may be enough to delay cell cycle progression in order to permit viral DNA replication, after which the cycle can progress. The B1R gene was probably acquired by vaccinia during viral evolution and in this process some of the characteristics of the original cellular protein, VRK1, were lost to adjust its role to viral needs. This is exemplified by a relaxation of its kinase specificity, while the human VRK1 is very specific in the phosphorylation of cellular proteins as p53 in Thr18 [80-82] or c-Jun [83], B1R hyperphosphorylates in multiple residues both p53 [72] and c-Jun [79], another transcription factor implicated in stress responses [84]. This differential specificity may be in part due to the fact that vaccinia virus has only one kinase, B1R, and it has to play multiple roles in viral life cycle and pathogenesis.

$\underline{E B V}$. The BZLF1 protein promotes phosphorylation of p53 that prevents its interaction with hdm2 and facilitates p53-dependent transcription at early stages of EBV infection [85]. But phosphorylation of p53 in its C-terminal region facilitates its degradation by interaction with non-mdm2 ubiquitin ligase [86, 87]. Thus at different phases of viral life cycle p53 has different and even opposite roles. Also in latent EBV infected cells the viral LMP1 protein indirectly induces multiple phosphorylation 
of p53 within its transactivation domain and results in transcriptional activation that may contribute to viral latency and to eventual development of nasopharyngeal carcinomas [88].

$\underline{\text { HHV6B. }}$. In some HHVB6 infected cells there is an indirect phosphorylation of p53 in Ser392, within its oligomerization domain, which is probably mediated by an unknown kinase and independent of CK2 or p38 kinases [89]. More recently it has been shown that in these infected cells p53 is also phosphorylated in Ser20 by CK1 [52], which reflect the activation of a virally induced stress response that will facilitate binding to its transcriptional coactivator p300 and thus initiate host cell defensive actions.

\section{P53 acetylation interference}

Hepatitis C virus: HCV induces the expression of 3-beta-hydroxysterol Delta24-reductase (DHCR24), which prevents p53 acetylation in lysines 373 and 382, and non-acetylated p53 is not functional because it cannot induce gene expression [90]. Thus, the lack of a p53 response in HCV infected cells might contribute to viral persistence.

Papillomaviruses: p53 acetylation interference paragraph. Recent data indicates that E6 of CRPV and HPV38 are able to prevent p300-mediated acetylation of p53 at lysine-382, probably through- a direct interaction with p300 [91]. This data is important because it is the first report demonstrating that the E6 protein of the skin cancer-associated papillomaviruses targets predominantly p53 acetylation via binding to p300, a transcriptional coactivator of p53, and does not induce degradation of p53 to immortalize primary keratinocytes and to induce tumors in an in vivo situation.

HCMV: The HCMV IE2 protein also contributes to the functional inactivation of p53 by interacting with the histone acetyl-transferase activity of the p300 and CBP coactivators. This interaction reduces acetylation of p53 and histone H3 [92]. The non acetylated p53 is still transcriptionally active, but its antiapoptotic activity is inhibited, probably by a change in the selection of promoters targeted by p53, and thus the activity of IE2 can be considered as oncogenic [92]. 
Adenovirus: This virus has the E1B protein that directly interacts with the acetyl transferase pCAF and also to a region near the p53 C-terminus in the region surrounding Lys320. The acetylation of p53 in is blocked, but the acetylation of histones by PCAF is not affected, suggesting that E1B functions by preventing a correct interaction between p53 and PCAF[41].

\section{Ubiquitylation of p53 by viral or cellular proteins}

Human Papillomavirus: HPV is associated with human cervical carcinoma, particularly types HPV16 and HPV18. The HPV life cycle is associated with the maturation of the epithelium. Thus viral replication takes place in the basal layer and the transit amplifying compartment, while the formation of viral infective particles and expression of late genes occurs in the maturing layers of the epithelium, where keratinization takes place and there is no cell division. HPV16 and HPV18 have an early gene, the E6 protein that is able to interact directly with the transactivation domain of p53 [93]. E6 is an E3 ubiquitin ligase that promotes ubiquitylation and subsequent degradation of p53 by the proteasome in cells that are actively replicating HPV [94]. The loss of p53, and the subsequent loss of its repressive effect on cell cycle progression [95], maintain the epithelial cells in a proliferative state and thus allows viral replication. The loss of p53 facilitated the replication of HPV16 mediated by the viral E2 protein [96, 97]. In addition the lack of p53 reduces the induction of apoptosis in infected cells preventing cell death and permits cell maturation to form infective viral particles. In HPV infected cells the effect of E6 on p53 is also accompanied by the interaction of E7 with retinoblastoma [98] resulting in a deregulation of the cell cycle independent of p53 [99]. The combined actions of both E6 and E7 contribute to genomic instability by abrogating cell cycle checkpoints [100], a process that can generate additional mutations in the pathway towards cancer. Recently it has been shown that an antagonist peptide against HPV16 E7 protein resulted in accumulation of p53 and induction of apoptosis by restoration of p53 activity, which in tumor xenographs showed therapeutic efficacy [101]. 
Hepes Simplex Virus: The ICP0 protein of HSV-1 is able to induce proteasome-dependent degradation of proteins and functions as an E3-ubiquitin ligase. ICP0 directly interacts with p53 independent of its binding to USP7, an ubiquitin specific protease that also interacts with ICP10 [102]. The loss of p53 induced by ICP0 thus interferes with the cellular ability to enter p53-mediated apoptosis, permitting the progression of the viral life cycle. But adenovirus ICP10 by sequestering USP7 can also induce a stabilization of p53, suggesting that the effects are different depending on the timing after infection [74].

EBV: During induction of EBV lytic cycle, there is a viral protein that facilitates p53 degradation by hdm2-independent ubiquitylation. The viral BZLF1 protein can function as a scaffold or adaptor of the ECS complex (Elongin B/C-cul2/5.SOCS-box protein), which is an ubiquitin ligase complex. This complex facilitates p53 degradation that has previously been phosphorylated in its C-terminal region and in that way downregulates the signal mediated by activated p53 [86, 87]. This complex regulation of p53 permits the execution of the different phases in the viral life cycle.

$\underline{K S H V}$ : In cells infected by KSVH LANA can also serve as an adaptor molecule for an E3 ubiquitin complex via a specific protein motif. This stimulates ubiquitylation and degradation of p53 [103]. Moreover, another KSHV viral protein, KbZIP that interacts with p53, possesses SUMO activity and inhibits p53-dependent transcription in KSHV-infected cells [56]. As an alternative virus-mediated mechanism for p53 degradation there are viral proteins that themselves lack E3 ligase activity, such as the immunomodulatory KSHV lytic protein vIRF4, that are capable of forming multi-protein complexes with ubiquitin ligase activity components. As an example, vIRF4 has recently been shown to interact with MDM2 and to facilitate the proteasome-mediated degradation of p53 [104].

\section{Interaction of viral proteins with Hdm2}

Cytomegalovirus: Human cytomegalovirus (HCMV) expresses the IE2-86 protein that interacts with hdm2 [105] leading to its degradation and thus prevents p53 ubiquitylation [105], which accumulates in nuclei twelve hours after HCMV infection [106]. Although still permissive for viral infection, cells 
lacking p53 show a decreased in accumulation of viral particles and a delay in viral DNA accumulation; these alterations can be recovered by normal p53, but not by p53 mutants. The expression of several viral proteins is altered in the absence of p53, such as the early replication protein UL44 and some of the late structural proteins, pp28 (UL99) and MCP (UL86). Localization of the major tegument protein pp65 (UL83) is also altered in p53(-/-) cells. Thus p53 appears to enhance HCMV replication and production of infectious virions [107].

Endothelial cells infected with HCMV are resistant to apoptosis [108, 109]. In infected endothelial cells there is an accumulation of p53, which is partly located in the cytosol as a result of blocking its nuclear localization signal and preventing its nuclear import, particularly in late stages of the infection [108, 109]. This is accompanied by a slowdown of the ubiquitylation [109], consistent with viral effect on hdm2.

HCMV infected fibroblasts $[110,111]$ present a senescence phenotype, accumulate p53 and have a hyperphosphorylated Rb, as well as an accumulation of the p16(INK4a) and reduction of p21[110]. This replicative senescence at early stages of infection increases the efficiency of infection and allows viral replication, effects that seem to be a consequence of the viral IE2-86 protein [110]. The IE2-86 protein induces Go/G1 and G1/S progression of the cell cycle, but then they slow down, probably as a consequence of its effect on p53, which is phosphorylated on Ser15 and acetylation resulting in its transcriptional activation and the increase in p16(Ink4a) and lack of p21 induction so that infected cells accumulate in the G2/M phase. Thus the dual effect of IE2 by inhibition of apoptosis and delay in cell cycle can permit completion of viral life cycle [111].

\section{Hdm2 phosphorylation by Akt induced by viruses}

Influenza ortho and paramixoviruses: Paramyxovirus and orthomyxoviruses interfere with p53 function in a complex way. Influenza infected cells have higher levels of p53 [112, 113], which are transcriptionally active, in part mediated by phosphorylation of p53[114] and might induce apoptosis [71]. Influenza virus also triggers an anti-apoptotic signal, indirectly mediated by PI3K-Akt, a survival pathway, early in infection in order to protect cells from an early death, but at later stages of the life cycle it induces expression of p21 and induces an apoptotic response $[112,113]$ that is both 
p53 dependent and independent [114]. Furthermore, p53 was required for virus induced cell-death [113], but the mechanism may in part be indirect and there might be an additional contribution by the induction of the interferon system [82]. One important component in this response partly mediated by p53 is due to modulation of the response by the phosphorylation of hdm2 by Akt [114]. Cells infected with influenza virus show an increase in the phosphorylation level of p53, which is dependent on the occurrence of viral RNA synthesis, indicating a cellular response to stress.

Thus, influenza infection activates sequentially two routes affecting p53. Initially in infected cells there is an activation of the PI3K-AKT that phosphorylates hdm2, leading to its proteolytic degradation [115], and thus increasing p53 levels [30]. This results in accumulation of p53 and activation of p53 inducible genes such as p21, a cell cycle inhibitor, and bax leading to induction of cell death by accumulation of p53 $[114,115]$. Thus influenza has a complex mechanism for modulating p53 dependent functions.

Paramyxoviruses are non-segmented negative-stranded RNA viruses and include viruses such as parainfluenza of which parainfluenza virus 5 (PIV5) is a prototype. Paramyxoviruses encode a protein $\mathrm{V}$ that plays a major role in regulation of viral RNA synthesis. This V protein has a conserved cysteine-rich C terminus that interacts with AKT [83]. AKT also contributes to a significant phosphorylation of P proteins from paramyxoviruses, which are essential cofactors in the viral RNA polymerase complex [115]. Inhibition of AKT reduces the level of PIV5 suggesting it is necessary for viral replication [115]. The role of Akt-mdm2-p53 is a well known regulatory mechanism of their functions [29, 30, 116].

Respiratory Syncytial virus: RSV, a paramyxovirus, is the cause of major respiratory problems and even death in infancy. RSV infects airway epithelial cells causing bronchiolitis in infants, and lifethreatening pneumonia in immunosuppressed individuals. RSV activates hdm2 shortly after infection, followed by a reduction in p53 levels [86]. RSV activates AKT, which phosphorylates and stabilizes hdm2, thus activating p53 degradation and causing a delay of apoptosis in primary human airway epithelial cells. This p53 down-regulation correlates with increased airway epithelial cell longevity, and this effect of RSV infection can be antagonized by nutlin-3 [117]. 


\section{Induction of p53 by interferon}

Many viruses induce interferon production in infected cells [118]. Type I interferons (IFN-alpha/beta) induce the transcription of tumor suppressor p53 and sensitize primary mouse embryonic fibroblasts to p53-mediated apoptosis by oncolytic viruses, such as vesicular stomatitis virus (VSV) [119]. But interferon can also induce downregulation of p53 levels in infected cells by VSV, probably reflecting different temporal roles during the infection [120]. A similar downregulation of p53 has also been observed in cells infected with several non-oncogenic viruses, including encephalomyocarditis virus and human parainfluenza virus type 3 [120]. These apparently contradictory effects may reflect a differential role for p53 in the course of the infection.

\section{p53 targeted therapies for viral infection control: Prospects for antiviral therapies or virus-}

\section{associated diseases}

Infected cells are located in areas accessible to viral particles, and thus highly likely to also be reached by drugs. Antiviral therapies should not only be directed to the virus, but also to manipulate the response of the infected cell with a therapeutic purpose, allowing the possibility of cutting short the initial spread of a viral infection, and in that way reducing its severity. The p53 pathway is the key element in the host cell stress response, including infections, and therefore might be a suitable target for pharmacological development. Some experimental evidence for an antiviral role for p53 has been demonstrated in the super-p53 mice, a mouse that contains three copies of the p53 gene, and express slightly higher levels of this protein [121]. These mice were more resistant to infection by VSV and replication because there is an increase in apoptosis as a consequence of p53, thus inhibiting the dissemination of the virus [122]. This illustrates that increasing p53 levels in infected cells might control an infection.

The p53 pathway is altered by mutations in many cancers, and is the subject of intense therapeutic interest [123-125], which can provide a conceptual framework for its application to viral infections. For example rescue of p53 function in lung tumors selectively affects the proliferating tumor cells, resulting in their elimination [126, 127]. Therefore, it seems reasonable than a similar 
concept could be applied to the control of infectious diseases, particularly viruses. If p53 mediated responses are eliminated or interfered with in a variety of viral infections, it might be possible that some strategies aiming to recover or maintain p53 function might be of use to abort viral infections, which in some cases might be critical, such as in the control of their bioterrorist use, or in cases of acute effects requiring urgent attention. Among the infections that might be of interest are those related to poxviruses. An alternative use of p53 rescue drugs would be for application to latent or chronic viral infections with the aim of eliminating infected cells.

Rescue mutations in cancer, of which Y220C is the paradigm, provided a structural framework for development of new p53 therapies [128]. But in the case of infections, p53 is a normal protein that interacts with a viral protein. Knowledge of the structure between p53 and proteins from pathogenic human viruses is necessary to have a framework to start developing novel drugs aiming at p53, which can be based on large screening targeting this interaction, but, unfortunately the structure of p53-viral protein is only known in the case of SV40 large T antigen [35].

Partial rescue of normal p53 function have been shown to interfere with the success of viral infection. The reactivation of p53 function by preventing its degradation by hdm2, as is the case of nutlins might contribute to control of virus-induced diseases, since p53 accumulation will stop cell cycle and induce apoptosis. Some of the drugs used in the context of cancer have already been applied to control of infected cells; particularly the use of nutlins that interferes with the p53-mdm2 interaction, peptides might also interfere with p53-viral protein interactions. Nutlins are small molecules that directly interact with the hdm2/mdm2 surface area required for hdm2 binding to p53; thus the binding of nutlins to mdm2 preventing the interaction with p53 and functionally rescuing p53-dependent functions [129]. Nutlins in control of viral infection might be useful if they induce cell death and thus interfere with the complete viral life cycle. Nutlin-3a induces massive level of apoptosis in cells harboring KSHV. In PEL (primary effusion lymphoma) cells the use of Nutlin-3a reactivates p53 induces massive level of apoptosis, suggesting this pathway was inactivated in these infected cells [130, 131]. Furthermore, the chemical reactivation of p53 by the Hdm2 antagonist Nutlin-3 led to unimpaired induction of p53 target genes as well as growth inhibition and apoptosis [132]. These results provide support for the use of p53 functional rescue with a therapeutic purpose. It 
is not known if a similar effect can be achieved in other pathology caused by KSHV. Also, the effect of RSV infection can be antagonized by nutlin-3. Nutlin increases the level of p53 in RSV infected cells causing an early cell death [86]. These results are important as proof of concept for targeting p53 functions in virally infected cells. The use of nutlin-3 in Burkitt lymphoma cells disrupts the interaction of p53 with mdm2 and facilitates induction of apoptosis [133]. Also in lymphoblastoid cells infected with EBV the treatment with nutlin-3A and p53 restoration there is an induction of apoptosis and thus interference with viral infection pointing to its potential usefulness with a therapeutic purpose [134].

Very recently a novel p53 functional recue has been reported. In this approach the suppression of p53 by HdmX, an hdm2 related protein, can be overcome by stapling the p53 helix that should interact with HdmX resulting in an activation of p53 function [135]. In this approach the HdmX protein is blocked by a peptide containing two substitutions and derived from the p53 alpha-helix. These peptides also block the effect of Hdm2 [135].

The recovery of p53 function in infected cells can have two major applications. In acute infections the stabilization of p53 can result in its death before completion of viral life cycle, thus limiting the magnitude of the infection. This will be very useful for infections like poxviruses, or in the case of viruses such as Ebola, Lassa or hemorrhagic fevers, that have no treatment. In these situations even some drug toxicity might acceptable given the short duration of the treatment and the dramatic consequences of these infections. In all cases it is of great interest to study the role of p53 rescue drugs in animal models to identify new ways for controlling viral infections. The initial evidence obtained with RSV and KSHV clearly indicate what might become a very promising therapeutic approach.

Another area of great potential but that has not received any attention in the context of antiviral therapies refers to the potential use of kinase inhibitors to control viral infections., particularly at a time in which there is a boom in development of kinase inhibitors. These inhibitors can target either kinases in cellular pathways used by viruses, or alternatively viral kinases. Among the cellular kinases, the PI3K-Akt pathway is a prime candidate since it is affected by some viruses (Table 1), such as RSV [117], and there is a large number of inhibitors available or in development 
[136]. Regarding viral kinases, up to now only one the B1R kinase form poxviruses virus has been identified as affecting the pre pathway [72], thus development of specific inhibitors for this kinase is a challenge, since its eventual utilization includes viruses such as smallpox, which is a potential bioterrorist threat.

The development of specific drugs targeting the interaction of p53 with viral proteins might provide a conceptual framework to design specific strategies to interfere with the viral life cycle. These drugs should interfere with the interaction between the viral protein and $\mathrm{p} 53$, so that this latter molecule can initiate the appropriate stress response to eliminate the infected cell before viral replication takes place. In this context viral kinases should receive more attention as specific targets for inhibition of viral functions. Particularly now, that the inhibition of many members the human kinome is the target of intense pharmaceutical research. Existing inhibitors of human kinases may affect viral life cycles; and is possibility that should also be explored with a therapeutic aim.

\section{REFERENCES}

[1] Horn HF, Vousden KH. Coping with stress: multiple ways to activate p53. Oncogene. 2007;26:1306-16.

[2] Vousden KH, Lane DP. p53 in health and disease. Nat Rev Mol Cell Biol. 2007;8:275-83.

[3] Joerger AC, Fersht AR. Structural biology of the tumor suppressor p53. Annu Rev Biochem. 2008;77:557-82.

[4] Vousden KH, Prives C. Blinded by the Light: The Growing Complexity of p53. Cell. 2009;137:413-31.

[5] Lu X. Tied Up in Loops: Positive and Negative Autoregulation of p53. Cold Spring Harb Perspect Biol. 2010;2:a000984.

[6] Schwartz D, Rotter V. p53-dependent cell cycle control: response to genotoxic stress. Semin Cancer Biol. 1998;8:325-36.

[7] Chipuk JE, Green DR. Dissecting p53-dependent apoptosis. Cell Death Differ. 2006;13:994-1002.

[8] Crighton D, Wilkinson S, O'Prey J, Syed N, Smith P, Harrison PR, et al. DRAM, a p53-induced modulator of autophagy, is critical for apoptosis. Cell. 2006;126:121-34.

[9] Xue W, Zender L, Miething C, Dickins RA, Hernando E, Krizhanovsky V, et al. Senescence and tumour clearance is triggered by p53 restoration in murine liver carcinomas. Nature. 2007;445:656-60.

[10] Taylor WR, Stark GR. Regulation of the G2/M transition by p53. Oncogene. 2001;20:1803-15.

[11] Oren M. Decision making by p53: life, death and cancer. Cell Death Differ. 2003;10:431-42.

[12] Laptenko O, Prives C. Transcriptional regulation by p53: one protein, many possibilities. Cell Death Differ. 2006;13:951-61.

[13] Kaustov L, Yi GS, Ayed A, Bochkareva E, Bochkarev A, Arrowsmith CH. p53 transcriptional activation domain: a molecular chameleon? Cell Cycle. 2006;5:489-94.

[14] Feng Z, Hu W, Rajagopal G, Levine AJ. The tumor suppressor p53: cancer and aging. Cell Cycle. 2008;7:842-7. 
[15] Meek DW. Tumour suppression by p53: a role for the DNA damage response? Nat Rev Cancer. 2009;9:714-23.

[16] Halazonetis TD. Constitutively active DNA damage checkpoint pathways as the driving force for the high frequency of p53 mutations in human cancer. DNA Repair (Amst). 2004;3:1057-62.

[17] Efeyan A, Serrano M. p53: guardian of the genome and policeman of the oncogenes. Cell Cycle. 2007;6:1006-10.

[18] Meek DW, Anderson CW. Posttranslational Modification of p53: Cooperative Integrators of Function. Cold Spring Harb Perspect Biol. 2009;1:a000950.

[19] Teufel DP, Bycroft M, Fersht AR. Regulation by phosphorylation of the relative affinities of the $\mathrm{N}$-terminal transactivation domains of p53 for p300 domains and Mdm2. Oncogene. 2009;28:2112-8.

[20] Lee CW, Ferreon JC, Ferreon AC, Arai M, Wright PE. Graded enhancement of p53 binding to CREB-binding protein (CBP) by multisite phosphorylation. Proc Natl Acad Sci U S A. 2010;107:19290-5.

[21] Sakaguchi K, Herrera JE, Saito S, Miki T, Bustin M, Vassilev A, et al. DNA damage activates p53 through a phosphorylation-acetylation cascade. Genes Dev. 1998;12:2831-41.

[22] Perry ME. The Regulation of the p53-mediated Stress Response by MDM2 and MDM4. Cold Spring Harbor Perspect Biol. 2010;2:a000968.

[23] Iwakuma T, Lozano G. MDM2, an introduction. Mol Cancer Res. 2003;1:993-1000.

[24] Moll UM, Petrenko O. The MDM2-p53 interaction. Mol Cancer Res. 2003;1:1001-8.

[25] Brooks CL, Gu W. p53 ubiquitination: Mdm2 and beyond. Mol Cell. 2006;21:307-15.

[26] Alarcon-Vargas D, Ronai Z. p53-Mdm2--the affair that never ends. Carcinogenesis. 2002;23:541-7.

[27] Kussie PH, Gorina S, Marechal V, Elenbaas B, Moreau J, Levine AJ, et al. Structure of the MDM2 oncoprotein bound to the p53 tumor suppressor transactivation domain. Science. 1996;274:948-53.

[28] Meek DW, Knippschild U. Posttranslational modification of MDM2. Mol Cancer Res. 2003;1:1017-26.

[29] Mayo LD, Donner DB. A phosphatidylinositol 3-kinase/Akt pathway promotes translocation of Mdm2 from the cytoplasm to the nucleus. Proc Natl Acad Sci U S A. 2001;98:11598-603.

[30] Blattner C, Hay T, Meek DW, Lane DP. Hypophosphorylation of Mdm2 augments p53 stability. Mol Cell Biol. 2002;22:6170-82.

[31] Khosravi R, Maya R, Gottlieb T, Oren M, Shiloh Y, Shkedy D. Rapid ATM-dependent phosphorylation of MDM2 precedes p53 accumulation in response to DNA damage. Proc Natl Acad Sci U S A. 1999;96:14973-7.

[32] Goldberg Z, Vogt Sionov R, Berger M, Zwang Y, Perets R, Van Etten RA, et al. Tyrosine phosphorylation of Mdm2 by c-Abl: implications for p53 regulation. Embo J. 2002;21:3715-27.

[33] Reich NC, Levine AJ. Specific interaction of the SV40 T antigen-cellular p53 protein complex with SV40 DNA. Virology. 1982;117:286-90.

[34] Jiang D, Srinivasan A, Lozano G, Robbins PD. SV40 T antigen abrogates p53-mediated transcriptional activity. Oncogene. 1993;8:2805-12.

[35] Lilyestrom W, Klein MG, Zhang R, Joachimiak A, Chen XS. Crystal structure of SV40 large Tantigen bound to p53: interplay between a viral oncoprotein and a cellular tumor suppressor. Genes Dev. 2006;20:2373-82.

[36] Staib C, Pesch J, Gerwig R, Gerber JK, Brehm U, Stangl A, et al. p53 inhibits JC virus DNA replication in vivo and interacts with JC virus large T-antigen. Virology. 1996;219:237-46.

[37] Coelho TR, Almeida L, Lazo PA. JC virus in the pathogenesis of colorectal cancer, an etiological agent or another component in a multistep process? Virol J. 2010;7:42.

[38] Bhatia K, Goedert JJ, Modali R, Preiss L, Ayers LW. Merkel cell carcinoma subgroups by Merkel cell polyomavirus DNA relative abundance and oncogene expression. Int J Cancer. 2010;126:2240-6.

[39] Steegenga WT, Riteco N, Jochemsen AG, Fallaux FJ, Bos JL. The large E1B protein together with the E4orf6 protein target p53 for active degradation in adenovirus infected cells. Oncogene. 1998;16:349-57. 
[40] Wienzek S, Roth J, Dobbelstein M. E1B 55-kilodalton oncoproteins of adenovirus types 5 and 12 inactivate and relocalize p53, but not p51 or p73, and cooperate with E4orf6 proteins to destabilize p53. J Virol. 2000;74:193-202.

[41] Liu Y, Colosimo AL, Yang XJ, Liao D. Adenovirus E1B 55-kilodalton oncoprotein inhibits p53 acetylation by PCAF. Mol Cell Biol. 2000;20:5540-53.

[42] Han JP, Sabbatini P, Perez D, Rao L, Modha D, White E. The E1B 19K protein blocks apoptosis by interacting with and inhibiting the p53 inducible and death promoting Bax protein. Genes Dev. 1996;10.

[43] Debbas M, White E. Wild-type p53 mediates apoptosis by E1A, which is inhibited by E1B. Genes Dev. 1993;7:546-54.

[44] Soria C, Estermann FE, Espantman KC, O'Shea CC. Heterochromatin silencing of p53 target genes by a small viral protein. Nature. 2010;466:1076-81.

[45] Hall AR, Dix BR, O'Carroll SJ, Braithwaite AW. p53-dependent cell death/apoptosis is required for a productive adenovirus infection. Nat Med. 1998;4:1068-72.

[46] Yi F, Saha A, Murakami M, Kumar P, Knight JS, Cai Q, et al. Epstein-Barr virus nuclear antigen 3C targets p53 and modulates its transcriptional and apoptotic activities. Virology. 2009;388:236-47.

[47] Saha A, Murakami M, Kumar P, Bajaj B, Sims K, Robertson ES. Epstein-Barr virus nuclear antigen 3C augments Mdm2-mediated p53 ubiquitination and degradation by deubiquitinating Mdm2. J Virol. 2009;83:4652-69.

[48] Zhang Q, Gutsch D, Kenney S. Functional and physical interaction between p53 and BZLF1: implications for Epstein-Barr virus latency. Mol Cell Biol. 1994;14:1929-38.

[49] Mauser A, Saito S, Appella E, Anderson CW, Seaman WT, Kenney S. The Epstein-Barr virus immediate-early protein BZLF1 regulates p53 function through multiple mechanisms. $J$ Virol. 2002;76:12503-12.

[50] Takemoto M, Koike M, Mori Y, Yonemoto S, Sasamoto Y, Kondo K, et al. Human herpesvirus 6 open reading frame U14 protein and cellular p53 interact with each other and are contained in the virion. J Virol. 2005;79:13037-46.

[51] Lacroix A, Collot-Teixeira S, Mardivirin L, Jaccard A, Petit B, Piguet C, et al. Involvement of human herpesvirus-6 variant B in classic Hodgkin's lymphoma via DR7 oncoprotein. Clin Cancer Res. 2010;16:4711-21.

[52] MacLaine NJ, Oster B, Bundgaard B, Fraser JA, Buckner C, Lazo PA, et al. A central role for CK1 in catalyzing phosphorylation of the p53 transactivation domain at serine 20 after HHV6B viral infection. J Biol Chem. 2008;283:28563-73.

[53] Oster B, Kofod-Olsen E, Bundgaard B, Hollsberg P. Restriction of human herpesvirus 6B replication by p53. $J$ Gen Virol. 2008;89:1106-13.

[54] Gao SJ, Kingsley L, Hoover DR, Spira TJ, Rinaldo CR, Saah A, et al. Seroconversion to antibodies against Kaposi's sarcoma-associated herpesvirus-related latent nuclear antigens before the development of Kaposi's sarcoma. $N$ Engl J Med. 1996;335:233-41.

[55] Friborg J, Jr., Kong W, Hottiger MO, Nabel GJ. p53 inhibition by the LANA protein of KSHV protects against cell death. Nature. 1999;402:889-94.

[56] Park J, Seo T, Hwang S, Lee D, Gwack Y, Choe J. The K-bZIP protein from Kaposi's sarcomaassociated herpesvirus interacts with p53 and represses its transcriptional activity. $J$ Virol. 2000;74:11977-82.

[57] Suzuki T, Isobe T, Kitagawa M, Ueda K. Kaposi's sarcoma-associated herpesvirus-encoded LANA positively affects on ubiquitylation of p53. Biochem Biophys Res Commun. 2010;403:194-7.

[58] Shin YC, Nakamura H, Liang X, Feng P, Chang H, Kowalik TF, et al. Inhibition of the ATM/p53 signal transduction pathway by Kaposi's sarcoma-associated herpesvirus interferon regulatory factor 1. J Virol. 2006;80:2257-66.

[59] Lee SG, Rho HM. Transcriptional repression of the human p53 gene by hepatitis B viral X protein. Oncogene. 2000;19:468-71.

[60] Takada S, Kaneniwa N, Tsuchida N, Koike K. Cytoplasmic retention of the p53 tumor suppressor gene product is observed in the hepatitis B virus X gene-transfected cells. Oncogene. 1997;15:1895-901. 
[61] Doitsh G, Shaul Y. HBV transcription repression in response to genotoxic stress is p53dependent and abrogated by pX. Oncogene. 1999;18:7506-13.

[62] Wang JH, Yun C, Kim S, Chae S, Lee YI, Kim WH, et al. Reactivation of p53 in cells expressing hepatitis B virus X-protein involves p53 phosphorylation and a reduction of Hdm2. Cancer Sci. 2008;99:888-93.

[63] Iyer S, Groopman JD. Interaction of mutant hepatitis B X protein with p53 tumor suppressor protein affects both transcription and cell survival. Mol Carcinog. 2011.

[64] Lan KH, Sheu ML, Hwang SJ, Yen SH, Chen SY, Wu JC, et al. HCV NS5A interacts with p53 and inhibits p53-mediated apoptosis. Oncogene. 2002;21:4801-11.

[65] Deng L, Nagano-Fujii M, Tanaka M, Nomura-Takigawa Y, Ikeda M, Kato N, et al. NS3 protein of Hepatitis C virus associates with the tumour suppressor p53 and inhibits its function in an NS3 sequence-dependent manner. J Gen Virol. 2006;87:1703-13.

[66] Ariumi Y, Kaida A, Hatanaka M, Shimotohno K. Functional cross-talk of HIV-1 Tat with p53 through its C-terminal domain. Biochem Biophys Res Commun. 2001;287:556-61.

[67] Gualberto A, Baldwin AS, Jr. p53 and Sp1 interact and cooperate in the tumor necrosis factorinduced transcriptional activation of the HIV-1 long terminal repeat. J Biol Chem. 1995;270:19680-3.

[68] Sawaya BE, Khalili K, Mercer WE, Denisova L, Amini S. Cooperative actions of HIV-1 Vpr and p53 modulate viral gene transcription. J Biol Chem. 1998;273:20052-7.

[69] Wang X, Shen Y, Qiu Y, Shi Z, Shao D, Chen P, et al. The non-structural (NS1) protein of influenza A virus associates with p53 and inhibits p53-mediated transcriptional activity and apoptosis. Biochem Biophys Res Commun. 2010;395:141-5.

[70] Li W, Wang G, Zhang H, Xin G, Zhang D, Zeng J, et al. Effects of NS1 variants of H5N1 influenza virus on interferon induction, TNFalpha response and p53 activity. Cell Mol Immunol. 2010;7:235-42.

[71] Shen Y, Wang X, Guo L, Qiu Y, Li X, Yu H, et al. Influenza A virus induces p53 accumulation in a biphasic pattern. Biochem Biophys Res Commun. 2009;382:331-5.

[72] Santos CR, Vega FM, Blanco S, Barcia R, Lazo PA. The vaccinia virus B1R kinase induces p53 downregulation by an Mdm2-dependent mechanism. Virology. 2004;328:254-65.

[73] Fedorov O, Marsden B, Pogacic V, Rellos P, Muller S, Bullock AN, et al. A systematic interaction map of validated kinase inhibitors with Ser/Thr kinases. Proc Natl Acad Sci U S A. 2007; 104:20523-8.

[74] Boutell C, Everett RD. Herpes simplex virus type 1 infection induces the stabilization of p53 in a USP7- and ATM-independent manner. J Virol. 2004;78:8068-77.

[75] Castillo JP, Frame FM, Rogoff HA, Pickering MT, Yurochko AD, Kowalik TF. Human cytomegalovirus IE1-72 activates ataxia telangiectasia mutated kinase and a p53/p21-mediated growth arrest response. $J$ Virol. 2005;79:11467-75.

[76] Banham AH, Smith GL. Vaccinia virus gene B1R encodes a 34-kDa serine/threonine protein kinase that localizes in cytoplasmic factories and is packaged into virions. Virology. 1992;191:803-12.

[77] Rempel RE, Anderson MK, Evans E, Traktman P. Temperature-sensitive vaccinia virus mutants identify a gene with an essential role in viral replication. $J$ Virol. 1990;64:574-83.

[78] Wali A, Strayer DS. Infection with vaccinia virus alters regulation of cell cycle progression. DNA Cell Biol. 1999;18:837-43.

[79] Santos CR, Blanco S, Sevilla A, Lazo PA. Vaccinia virus B1R kinase interacts with JIP1 and modulates c-Jun-dependent signaling. J Virol. 2006;80:7667-75.

[80] Lopez-Borges S, Lazo PA. The human vaccinia-related kinase 1 (VRK1) phosphorylates threonine-18 within the mdm-2 binding site of the p53 tumour suppressor protein. Oncogene. 2000;19:3656-64.

[81] Vega FM, Sevilla A, Lazo PA. p53 Stabilization and accumulation induced by human vacciniarelated kinase 1. Mol Cell Biol. 2004;24:10366-80.

[82] Valbuena A, Castro-Obregon S, Lazo PA. Downregulation of VRK1 by p53 in Response to DNA Damage Is Mediated by the Autophagic Pathway. PLoS ONE. 2011;6:e17320. 
[83] Sevilla A, Santos CR, Barcia R, Vega FM, Lazo PA. c-Jun phosphorylation by the human vaccinia-related kinase 1 (VRK1) and its cooperation with the N-terminal kinase of c-Jun (JNK). Oncogene. 2004;23:8950-8.

[84] Weston CR, Davis RJ. The JNK signal transduction pathway. Curr Opin Cell Biol. 2007;19:1429.

[85] Sato Y, Shirata N, Murata T, Nakasu S, Kudoh A, Iwahori S, et al. Transient increases in p53responsible gene expression at early stages of Epstein-Barr virus productive replication. Cell Cycle. 2010;9:807-14.

[86] Sato Y, Kamura T, Shirata N, Murata T, Kudoh A, Iwahori S, et al. Degradation of phosphorylated p53 by viral protein-ECS E3 ligase complex. PLoS Pathog. 2009;5:e1000530.

[87] Sato Y, Shirata N, Kudoh A, Iwahori S, Nakayama S, Murata T, et al. Expression of Epstein-Barr virus BZLF1 immediate-early protein induces p53 degradation independent of MDM2, leading to repression of p53-mediated transcription. Virology. 2009;388:204-11.

[88] Li L, Guo L, Tao Y, Zhou S, Wang Z, Luo W, et al. Latent membrane protein 1 of Epstein-Barr virus regulates p53 phosphorylation through MAP kinases. Cancer Lett. 2007;255:219-31.

[89] Oster B, Bundgaard B, Hupp TR, Hollsberg P. Human herpesvirus 6B induces phosphorylation of p53 in its regulatory domain by a CK2- and p38-independent pathway. J Gen Virol. 2008;89:87-96.

[90] Nishimura T, Kohara M, Izumi K, Kasama Y, Hirata Y, Huang Y, et al. Hepatitis C virus impairs p53 via persistent overexpression of 3beta-hydroxysterol Delta24-reductase. J Biol Chem. 2009;284:36442-52.

[91] Muench P, Probst S, Schuetz J, Leiprecht N, Busch M, Wesselborg S, et al. Cutaneous papillomavirus E6 proteins must interact with p300 and block p53-mediated apoptosis for cellular immortalization and tumorigenesis. Cancer Res. 2010;70:6913-24.

[92] Hsu CH, Chang MD, Tai KY, Yang YT, Wang PS, Chen CJ, et al. HCMV IE2-mediated inhibition of HAT activity downregulates p53 function. Embo J. 2004;23:2269-80.

[93] Scheffner M, Werness BA, Huibregtse JM, Levine AJ, Howley PM. The E6 oncoprotein encoded by human papillomavirus types 16 and 18 promotes the degradation of p53. Cell. 1990;63:1129-36.

[94] Thomas M, Matlashewski G, Pim D, Banks L. Induction of apoptosis by p53 is independent of its oligomeric state and can be abolished by HPV18 E6 through ubiquitin mediated degradation. Oncogene. 1996;13:265-73.

[95] Thomas M, Pim D, Banks L. The role of the E6-p53 interaction in the molecular pathogenesis of HPV. Oncogene. 1999;18:7690-700.

[96] Lepik D, Ustav M. Cell-specific modulation of papovavirus replication by tumor suppressor protein p53. $J$ Virol. 2000;74:4688-97.

[97] Brown C, Kowalczyk AM, Taylor ER, Morgan IM, Gaston K. P53 represses human papillomavirus type 16 DNA replication via the viral E2 protein. Virol J. 2008;5:5.

[98] Dyson N, Howley PM, Munger K, Harlow E. The human papilloma virus-16 E7 oncoprotein is able to bind to the retinoblastoma gene product. Science. 1989;243:934-7.

[99] White AE, Livanos EM, Tlsty TD. Differential disruption of genomic integrity and cell cycle regulation in normal human fibroblasts by the HPV oncoproteins. Genes Dev. 1994;8:666-77.

[100] Thomas JT, Laimins LA. Human papillomavirus oncoproteins E6 and E7 independently abrogate the mitotic spindle checkpoint. J Virol. 1998;72:1131-7.

[101] Guo C, Liu K, Zheng Y, Luo H, Chen H, Huang L. Apoptosis induced by an antagonist peptide against HPV16 E7 in vitro and in vivo via restoration of p53. Apoptosis. 2011.

[102] Boutell C, Everett RD. The herpes simplex virus type 1 (HSV-1) regulatory protein ICP0 interacts with and Ubiquitinates p53. J Biol Chem. 2003;278:36596-602.

[103] Cai QL, Knight JS, Verma SC, Zald P, Robertson ES. EC5S ubiquitin complex is recruited by KSHV latent antigen LANA for degradation of the VHL and p53 tumor suppressors. PLoS Pathog. 2006;2:e116.

[104] Lee HR, Toth Z, Shin YC, Lee JS, Chang H, Gu W, et al. Kaposi's sarcoma-associated herpesvirus viral interferon regulatory factor 4 targets MDM2 to deregulate the p53 tumor suppressor pathway. J Virol. 2009;83:6739-47. 
[105] Zhang Z, Evers DL, McCarville JF, Dantonel JC, Huong SM, Huang ES. Evidence that the human cytomegalovirus IE2-86 protein binds mdm2 and facilitates mdm2 degradation. $J$ Virol. 2006;80:3833-43.

[106] Chen Z, Knutson E, Wang S, Martinez LA, Albrecht T. Stabilization of p53 in human cytomegalovirus-initiated cells is associated with sequestration of HDM2 and decreased p53 ubiquitination. J Biol Chem. 2007;282:29284-95.

[107] Casavant NC, Luo MH, Rosenke K, Winegardner T, Zurawska A, Fortunato EA. Potential role for p53 in the permissive life cycle of human cytomegalovirus. J Virol. 2006;80:8390-401.

[108] Wang J, Belcher JD, Marker PH, Wilcken DE, Vercellotti GM, Wang XL. Cytomegalovirus inhibits p53 nuclear localization signal function. $J$ Mol Med. 2001;78:642-7.

[109] Utama B, Shen YH, Mitchell BM, Makagiansar IT, Gan Y, Muthuswamy R, et al. Mechanisms for human cytomegalovirus-induced cytoplasmic p53 sequestration in endothelial cells. J Cell Sci. 2006;119:2457-67.

[110] Noris E, Zannetti C, Demurtas A, Sinclair J, De Andrea M, Gariglio M, et al. Cell cycle arrest by human cytomegalovirus 86-kDa IE2 protein resembles premature senescence. $J$ Virol. 2002;76:12135-48.

[111] Song YJ, Stinski MF. Inhibition of cell division by the human cytomegalovirus IE86 protein: role of the p53 pathway or cyclin-dependent kinase 1/cyclin B1. J Virol. 2005;79:2597-603.

[112] Technau-Ihling K, Ihling C, Kromeier J, Brandner G. Influenza A virus infection of mice induces nuclear accumulation of the tumorsuppressor protein p53 in the lung. Arch Virol. 2001;146:1655-66.

[113] Turpin E, Luke K, Jones J, Tumpey T, Konan K, Schultz-Cherry S. Influenza virus infection increases p53 activity: role of p53 in cell death and viral replication. J Virol. 2005;79:8802-11.

[114] Zhirnov OP, Klenk HD. Control of apoptosis in influenza virus-infected cells by up-regulation of Akt and p53 signaling. Apoptosis. 2007;12:1419-32.

[115] Sun M, Fuentes SM, Timani K, Sun D, Murphy C, Lin Y, et al. Akt plays a critical role in replication of nonsegmented negative-stranded RNA viruses. $J$ Virol. 2008;82:105-14.

[116] Gottlieb TM, Leal JF, Seger R, Taya Y, Oren M. Cross-talk between Akt, p53 and Mdm2: possible implications for the regulation of apoptosis. Oncogene. 2002;21:1299-303.

[117] Groskreutz DJ, Monick MM, Yarovinsky TO, Powers LS, Quelle DE, Varga SM, et al. Respiratory syncytial virus decreases p53 protein to prolong survival of airway epithelial cells. J Immunol. 2007;179:2741-7.

[118] Haller O, Kochs G, Weber F. The interferon response circuit: induction and suppression by pathogenic viruses. Virology. 2006;344:119-30.

[119] Takaoka A, Hayakawa S, Yanai H, Stoiber D, Negishi H, Kikuchi H, et al. Integration of interferon-alpha/beta signalling to p53 responses in tumour suppression and antiviral defence. Nature. 2003;424:516-23.

[120] Marques JT, Rebouillat D, Ramana CV, Murakami J, Hill JE, Gudkov A, et al. Downregulation of p53 by double-stranded RNA modulates the antiviral response. $J$ Virol. 2005;79:11105-14.

[121] Garcia-Cao I, Garcia-Cao M, Martin-Caballero J, Criado LM, Klatt P, Flores JM, et al. 'Super p53' mice exhibit enhanced DNA damage response, are tumor resistant and age normally. Embo J. 2002;21:6225-35.

[122] Munoz-Fontela C, Garcia MA, Garcia-Cao I, Collado M, Arroyo J, Esteban M, et al. Resistance to viral infection of super p53 mice. Oncogene. 2005;24:3059-62.

[123] Wiman KG. Restoration of wild-type p53 function in human tumors: strategies for efficient cancer therapy. Adv Cancer Res. 2007;97:321-38.

[124] Joerger AC, Fersht AR. The tumor suppressor p53: from structures to drug discovery. Cold Spring Harb Perspect Biol. 2010;2:a000919.

[125] Lane DP, Cheok CF, Lain S. p53-based Cancer Therapy. Cold Spring Harbor Perspect Biol. 2010:a001222.

[126] Feldser DM, Kostova KK, Winslow MM, Taylor SE, Cashman C, Whittaker CA, et al. Stagespecific sensitivity to p53 restoration during lung cancer progression. Nature. 2010;468:572-5. 
[127] Junttila MR, Karnezis AN, Garcia D, Madriles F, Kortlever RM, Rostker F, et al. Selective activation of p53-mediated tumour suppression in high-grade tumours. Nature. 2010;468:56771.

[128] Boeckler FM, Joerger AC, Jaggi G, Rutherford TJ, Veprintsev DB, Fersht AR. Targeted rescue of a destabilized mutant of p53 by an in silico screened drug. Proc Natl Acad Sci U S A. 2008;105:10360-5.

[129] Klein C, Vassilev LT. Targeting the p53-MDM2 interaction to treat cancer. Br J Cancer. 2004;91:1415-9.

[130] Sarek G, Kurki S, Enback J, Iotzova G, Haas J, Laakkonen P, et al. Reactivation of the p53 pathway as a treatment modality for KSHV-induced lymphomas. J Clin Invest. 2007;117:101928.

[131] Sarek G, Ojala PM. p53 reactivation kills KSHV lymphomas efficiently in vitro and in vivo: new hope for treating aggressive viral lymphomas. Cell Cycle. 2007;6:2205-9.

[132] Petre CE, Sin SH, Dittmer DP. Functional p53 signaling in Kaposi's sarcoma-associated herpesvirus lymphomas: implications for therapy. J Virol. 2007;81:1912-22.

[133] Renouf B, Hollville E, Pujals A, Tetaud C, Garibal J, Wiels J. Activation of p53 by MDM2 antagonists has differential apoptotic effects on Epstein-Barr virus (EBV)-positive and EBVnegative Burkitt's lymphoma cells. Leukemia. 2009;23:1557-63.

[134] Forte E, Luftig MA. MDM2-dependent inhibition of p53 is required for Epstein-Barr virus Bcell growth transformation and infected-cell survival. $J$ Virol. 2009;83:2491-9.

[135] Bernal F, Wade M, Godes M, Davis TN, Whitehead DG, Kung AL, et al. A Stapled p53 Helix Overcomes HDMX-Mediated Suppression of p53. Cancer Cell. 2010;18:411-22.

[136] McNamara CR, Degterev A. Small-molecule inhibitors of the PI3K signaling network. Future Med Chem. 2011;3:549-65. 
Table 1

\begin{tabular}{|c|c|c|c|}
\hline $\begin{array}{c}\text { Viral mechanism of } \\
\text { interference with p53 }\end{array}$ & Virus & Viral Protein & Ref. \\
\hline Inhibition of TP53 gene expression & HIV1 & Tat & [66] \\
\hline Interaction with p53 DNA binding domain & $\begin{array}{l}\text { SV40 } \\
\text { JCV } \\
\text { HHV8 (KSHV) } \\
\text { HHV6B } \\
\text { Adenovirus } \\
\text { Influenza } \\
\text { HCV }\end{array}$ & $\begin{array}{l}\text { Large T antigen } \\
\text { Large T antigen } \\
\text { K-bZIP (K8) } \\
\text { U14 } \\
\text { E1B/E4-ORF6 } \\
\text { NS1 } \\
\text { NS5A }\end{array}$ & $\begin{array}{l}{[33]} \\
{[36]} \\
{[56]} \\
{[50]} \\
{[39,40]} \\
{[69]} \\
{[65]}\end{array}$ \\
\hline Interaction with p53 C-terminus & $\begin{array}{l}\text { EBV (latent) } \\
\text { EBV (lytic) } \\
\text { KSHV }\end{array}$ & $\begin{array}{l}\text { EBNA-3C } \\
\text { BZLF1 } \\
\text { K-bZIP }\end{array}$ & $\begin{array}{l}{[46,47]} \\
{[48]} \\
{[56]}\end{array}$ \\
\hline p53 phosphorylation & $\begin{array}{l}\text { Vaccinia } \\
\text { EBV }\end{array}$ & $\begin{array}{l}\text { B1R } \\
\text { LMP1 (indirectly) }\end{array}$ & $\begin{array}{l}{[72]} \\
{[88]}\end{array}$ \\
\hline $\begin{array}{l}\text { Interaction with regulatory proteins (ATM) } \\
\text { of p53 }\end{array}$ & HHV8 (KSHV) & vIRF1/LANA & [58] \\
\hline Inhibition of p53 dependent transcription & $\begin{array}{l}\text { HIV-1 } \\
\text { Adenovirus } \\
\text { HBV } \\
\text { HCV } \\
\text { HHV6B }\end{array}$ & $\begin{array}{l}\text { Vpr (indirect) } \\
\text { E4-ORF3 } \\
\mathrm{X} \\
\text { NS5A } \\
\text { ORF-1(DR7) }\end{array}$ & $\begin{array}{l}68] \\
{[44]} \\
{[61]} \\
{[65]} \\
{[51]}\end{array}$ \\
\hline $\begin{array}{l}\text { Prevention of p53 acetylation } \\
\text { (modifies specificity of p53-dependent } \\
\text { transcription) }\end{array}$ & $\begin{array}{l}\text { HCV } \\
\text { HCMV } \\
\text { Adenovirus }\end{array}$ & $\begin{array}{l}\text { Induction of cellular DHCR24 } \\
\text { IE2-86 } \\
\text { E1B/E4-ORF6 }\end{array}$ & $\begin{array}{l}{[90]} \\
{[92]} \\
{[41]}\end{array}$ \\
\hline $\begin{array}{l}\text { Ubiquitylation of p53 by viral E3-Ubiqitin } \\
\text { ligases }\end{array}$ & $\begin{array}{l}\text { HPV } \\
\text { HSV } \\
\text { HHV8(KSHV) } \\
\text { EBV }\end{array}$ & $\begin{array}{l}\text { E6 } \\
\text { ICP0 } \\
\text { LANA (indirectly) } \\
\text { BZLF1 (indirectly) }\end{array}$ & $\begin{array}{l}93] \\
{[102]} \\
{[103]} \\
{[86,87]}\end{array}$ \\
\hline Phosphorylation of mdm2 by Akt & $\begin{array}{l}\text { RSV } \\
\text { Influenza } \\
\text { PIV5 }\end{array}$ & $\begin{array}{l}\text { ? } \\
? \\
\text { V protein }\end{array}$ & $\begin{array}{l}{[117]} \\
{[112]} \\
{[115]}\end{array}$ \\
\hline Interaction with hdm2 & $\begin{array}{l}\text { HCMV } \\
\text { HHV8(KSHV) }\end{array}$ & $\begin{array}{l}\text { IE2-86 } \\
\text { vIRF4 }\end{array}$ & $\begin{array}{l}{[105]} \\
{[104]}\end{array}$ \\
\hline $\begin{array}{l}\text { Indirect p53 downregulation induced by } \\
\text { interferons }\end{array}$ & $\begin{array}{l}\text { EMCV } \\
\text { HPIV3 } \\
\text { VSV }\end{array}$ & & $\begin{array}{l}{[120]} \\
{[120]} \\
{[119,120]}\end{array}$ \\
\hline
\end{tabular}




\section{$\underline{\text { FIGURE LEGENDS }}$}

Figure 1. Interaction between p53 and hdm2 and their autoregulatory loop. Steps where viruses interfere with the p53-hdm2 stress response to permit a successful viral life cycle. In the cases in which viruses inhibit p53 dependent transcription, the action of the viral protein has been placed in the branch or gene with which it has been reported, but other p53 dependent genes might also be affected. Vacc: vaccinia virus. SV40: simian virus 40. JCV: JC virus. Adv: Adenovirus. HCMV: human cytomegalovirus. Inf.: Influenza virus. HPV: human papillomaviruses. HHV: human herpes virus. KSHV: Kaposi sarcoma herpes virus. 